\title{
AEROMAGNETIC AND BOUGUER GRAVITY MAP OF TWIN SISTERS DUNITE, NORTHWESTERN WASHINGTON \\ By
}

G.A. Thompson

GEOPHYSICAL INVESTIGATIONS

MAP GP-901

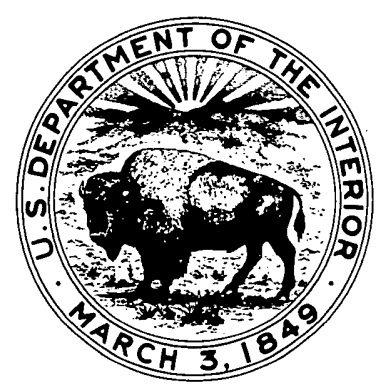

PUBLISHED BY THE U.S. GEOLOGICAL SURVEY WASHINGTON. D.C. 20244 